\title{
EL ESCUPITAJO DE LUNA O ESMERALDA DE LOS FILÓSOFOS ALGUNAS NOTAS MÁS SOBRE CIENCIA MODERNA Y POSTMODERNA
}

\author{
Quintín RACIONERO
}

En el número 21 (1999) de la madrileña Revista de Filosofía, y acogiéndome a una hospitalidad que no imponia como condición el que, dada una controversia cientifica, una parte pueda escribir cuantas páginas guste y la otra sólo siete, publiqué un ensayo, que, con el título de "No después sino distinto", recogía el contenido completo de mi intervención en un debate sobre "Ciencia moderna y postmoderna", que tuvo lugar en la Fundación Juan March los dias 19 y 21 de mayo de 1998. Como ya en ese artículo expliqué los motivos que me inclinaban a restaurar la escritura integra de un texto del que, en el Cuaderno editado por la citada Fundación ", sólo llegué a publicar un breve resumen, no voy a repetirlos ahora. Anuncié alli, de todos modos, que daria una réplica a las críticas que contra tal resumen habian formulado los ponentes del debate, Javier Echeverría y José Manuel Sánchez Ron. $Y$ eso es lo que hago a continuación, sin más preludios. Aunque quizás merezca la pena añadir que lo hago por dos razones de las que he descartado de antemano cualquier intencionalidad personal. La primera es que creo honestamente, tras la escrupulosa lectura de esas criticas, que los malentendidos sobre la relación entre la postmodernidad y la ciencia son abora mayores que al comienzo del debate. Y la segunda, que mantengo una activa militancia contra la cláusula que, con mordaz ironía, Michel Callon ha propuesto para el departamento de Física de su imaginario "Institut for Advanced Studies". A saber: la de que no se permitirá la entrada a quienes no muestren "un espiritu de lucha y deter-

1 Ciencia moderna y postmoderna, Fundación Juan March, Cuadernos del Seminario público, 2, Madrid, 1998. Las citas que intercalo en el texto remiten siempre a esta publicación sin otra referencia que la página.

ÉNDOXA: Series Filosóficas, n. ${ }^{\circ} 13,2000$, pp. 55-84. UNED, Madrid 
minación para ocultar y/o silenciar a todos aquellos que, no siendo fisicos, se otorgan el derecho de hablar sobre fisica de modos distintos a los que pueden leerse en los libros de texto de fisica" ${ }^{2}$. Si algún lector decide acompañarme en esta aventura tansgresora, comprobará que seguramente no son sólo fisicos los que verían con buenos ojos que una tal cláusula llegara de verdad a promulgarse.

Los alquimistas de la Praga rodolfina - John Dee o el desorejado Edward Kelley, habitantes de los lóbregos sótanos del castillo de Hradcany, son los más famosos de ellos - usaban una planta rara y viscosa, nacida, como la mandrágora o la lunaria mayor, al pie de los patíbulos, a la que, por su húmeda inconsistencia, llamaron escupitajo de luna y, por su presunta capacidad de catalizar el oro, esmeralda de los filósofos. Las propiedades de esta planta son extraordinarias. No se disuelve, como todas las otras, en el vinagre, pero, en cambio, si se la introduce en un frasco hermético, se destruye a sí misma, exhalando, al reabrir el frasco, un hedor de excrementos. Su vida es muy corta: exclusivamente nocturna, desaparece sin dejar huella a la salida del sol. Durante ese breve tiempo, guarda siempre una extraña frialdad, tan perceptible al tacto como la piel de un difunto, que no se modifica ni siquiera a las más altas temperaturas. Y cuando por fin se deslíe en el atanor, produce un agua turbia, que pasa del color celeste al púrpura y luego se aclara hasta el amarillo oro, antes de convertirse, una vez retirada del fuego, en un denso polvo deslumbrantemente blanco.

Usando de esta planta la película gelatinosa que precede a su transformación en polvo, a fin de amalgamar el azufre y el mercurio, Edward Kelley obtuvo, ante los ojos asombrados de Rodolfo II, una gruesa pepita de oro la noche del 6 de abril de 1587. No volvió a lograrlo más —o no disponemos de las correspondientes descripciones-, por lo que, perdido el favor del emperador, quebradas ambas piernas en sendos intentos de huída y enfrentado a una inminente condena por traición, se suicidó el 1 de noviembre de 1597 ingiriendo

2 M. CALlon "Whose Imposture? Physicists at War with the $3^{\text {th }}$ Person", Social Studies of Science, 29/2, abril 1999, p. 286. Se trata de la (hasta ahora) última respuesta al libro de SoKAL \& BRICMONT, Impostures intellectuelles, París, Odile Jacob, 1997. 
un veneno fulminante ${ }^{3}$. Esos últimos años que pasó en la cárcel no fueron improductivos, de todas formas. Quizás para recuperar la confianza de su rey o simplemente por dejar testimonio de su trabajo, escribió un De lapide philosophorum - uno más, hay decenas de ellos-, siendo este suyo el que ha conservado una mayor reputación por la fama de quien, al menos una vez, fabricó de verdad oro. Es un texto abstruso, de un latín difícil y una terminología apenas comprensible, aunque fascinante en sus evocaciones. Con todo, cuando el lector consigue entender una secuencia completa de la obra, no le acompaña de ordinario un sentimiento de conformidad, tal vez de vértigo, sino únicamente de decepción. Inspirada, según dice, en un viejo manuscrito anónimo, al que, no obstante, califica de indescifrable, describe la fusión del azufre y el mercurio en términos de una ceremonia nupcial. Matrimonio a todas luces contra natura, el escupitajo de luna es presentado entonces como el lubricante preciso para consumarlo. Esta función se relata en todos sus detalles, morosa, pormenorizadamente, unas veces con delectación y otras veces con un terror ingenuo, pero siempre en forma plana y confusa, sin distinguir los fenómenos de sus causas, los procesos empíricos constatables de la narración de las operaciones llevadas a cabo, los cómo de los porqué. Y, sin embargo, no es eso lo que provoca decepción, sino un hecho diferente. A saber: el que el autor no se interrogue en ningún instante sobre los fundamentos y los fines de ese prolijo relato, de cuya íntima coherencia, y del valor de sus supuestos creenciales, no se distancia jamás.

Los sucesivos hitos de la crítica filosófica a - dicho grosso modo- «la ciencia", en particular los que se han producido en nuestro siglo, abundan en un sentimiento de decepción muy semejante. No es una decepción, desde luego, que se dirija a la práctica científica en sí, cuyas polémicas tienen siempre un elevado componente de especialización intratextual, sino a la terca ignorancia de los presupuestos que a veces involucra, a la inane globalidad con que a menudo enuncia sus pretensiones teóricas y al candor con que, demasiado frecuentemente, convive con extraños compañeros de cama. Esos hitos de que hablo resultan bien conocidos y pueden detallarse, en su secuencialidad histórica precisa, con bastante exactitud; pero lo que importa consignar aquí es que por lo común no han caído en saco roto y que, incluso si ello ha tenido que

3 La descripción del experimento, así como algunas referencias biográficas sobre Edward Kelley (apodado Talbot en las crónicas de la época), aparecen recogidas en la conocida monografía sobre Rodolfo II de J. DEAUXOIS, L'empereur des alchimistes, París, JC Lattès, 1996, cap. 16. 
suceder siempre con la celosa oposición de los guardianes del stablishment científico en cada momento dominante, antes o después han dado lugar a cambios profundos en nuestras ideas sobre la significación de la ciencia y sobre la clase de actividad que realmente comporta. Las críticas de Heidegger al realismo naïf, a su juicio practicado por los saberes positivos, y su rápida recepción, pese a los reproches de los teóricos más duros del Empirismo lógico, en lo que hoy se conoce como "hermenéutica de las cienciasn; los esfuerzos del $2 .^{\circ}$ Wittgenstein por poner en claro la naturaleza social de los juegos del lenguaje y su incorporación, también aquí pese a múltiples suspicacias, al campo de los actuales programas de historia y sociología de la ciencia; las objeciones, en fin, de la Escuela de Frankfurt a la así llamada "teoría científica tradicional» y el surgimiento, una vez más cercado por las sospechas, de proyectos de investigación diseñados para analizar los vínculos entre la ciencia y cosas tales como los valores, el género o los procesos de dominación política y económica; todos estos episodios ( $\mathrm{y}$ otros más que pueden citarse) proporcionan testimonios incontrovertibles de que entre la "ciencia» y la "filosofía" media, no una contradicción entre dos modelos teóricos o dos "culturas", sino, más bien, un diálogo entre dos modos de encarar el conocimiento de lo real, que son -que se han mostrado de hecho- muchas veces complementarios y que, a pesar de todas las dificultades, pueden llegar a fértiles compromisos de adecuación e influjo mutuo. El que en este diálogo la ciencia (o mejor, como veremos, las ciencias) hayan solido proveer a la filosofía de criterios de realismo y control metódico en orden a la determinación de sus actividades propias no quita un ápice de verdad a la perspectiva contraria; esto es, al hecho de que también la filosofia ha cumplido un papel relevante, y habitualmente exitoso, a la hora de recordar a la ciencia la necesidad de que no se desentienda de la reflexión sobre sí misma y, por tanto, de que se haga cargo del suelo de prejuicios sobre el que se construyen los saberes y en cuya trama se edifican sus imágines.

En lo que atañe a la relación de la postmodernidad con la ciencia (que no agota ciertamente el contenido de la filosofía postmoderna, pero que, dentro de ella, juega un papel de primera magnitud), el caso no es distinto, al menos en sus aspectos funcionales, de estos que acabo de recordar. Lo he señalado en mi anterior escrito con una cautela que no juzgo ya necesario seguir manteniendo: no existe ninguna ciencia postmoderna, por la misma razón que no existe una ciencia heideggeriana o wittgensteniana o adorniana. Lo que la postmodernidad dice a propósito de la ciencia, se inscribe en esta cadena de hitos críticos y tiene que ver con los mismos asuntos de que también se trata en ellos. $\mathrm{O}$ sea: con asuntos que, siendo, sin duda, de orden metacientífico, plantean, con todo, 
problemas centrales para la interpretación de qué sea la ciencia, cómo se produce de facto en el ámbito de las sociedades avanzadas y qué rol cumple en la conformación de las convicciones comunitarias vigentes. En la medida en que el pensamiento postmoderno ha venido a introducir nuevas materias de meditación sobre el corpus argumental de aquellos hitos críticos ( $\mathrm{y}$, por tanto, en la medida en que él también se ha visto forzado a una confrontación con el stablishment de la epistemología al uso, por más porosa y fragmentada que ésta se encuentre), lo que la posibilidad de un debate sobre «ciencia moderna y postmoderna" parece demandar no es otra cosa, en mi opinión, que la apertura de un espacio de diálogo en el que se escuchen, ponderen y eventualmente se discutan las razones que asisten a las críticas formuladas por aquel pensamiento. Desdichadamente, a juzgar por las respuestas de José Manuel Sánchez Ron y Javier Echeverría que pueden leerse en el libro publicado por la Fundación March, esa posibilidad no se ha cumplido. Apegados por completo a una forma de discurso del que da la impresión que no pueden distanciarse, uno y otro, cada uno a su manera, han vuelto a explicarnos por enésima vez las propiedades que caracterizan al escupitajo de luna o esmeralda de los filósofos; de modo que el debate no ha tenido lugar.

Salvo en lo que concierne a qué debemos entender por postmodernidad (sobre lo que luego diré algunas palabras), Echeverría declara no sentirse objetado por mis argumentos. Y bien que lo celebro, pues no era mi intención turbar a quien juzgo un profesional competente y un respetado colega y amigo. Debo suponer, pues, que participa de mi observación sobre que la epistemología descripcionista, al modo de la formulada por Kuhn, se halla en dificultades para hacerse cargo de cuanto hay de contingente en esos factores exteriores latamente históricos, pero también, y de un modo muy concreto, políticos, sociales y económicos - de que ella misma se vale para su evaluación de la ciencia. Mi argumento era en este punto muy simple. Admitido que la descripción tenga una base histórica o, lo que es igual, que pueda subsumirse en un discurso de causas para determinadas situaciones o paradigmas de cultura, aquellos factores exteriores no podrán ser sometidos al distanciamiento propio de la reflexión, a menos que se considere que no son forzosos, que se puede intervenir en ellos y que en eso consiste precisamente la tarea de una epistemología que no 
quiera conformarse con hacer de cronista oficial de los intereses implicados en la producción científica. Ahora bien, si estoy en lo cierto, o sea, si no sentirse objetado quiere decir que Echeverría admite la posibilidad de una epistemología crítica, que no se ajuste exclusivamente al papel de registrar los anales de las res scientiae, imagino entonces que estará de acuerdo en que la mera descripción del estado actual de la ciencia, dominada por el modelo de la tecnociencia, no puede ser sino el punto de arranque para lo que verdaderamente importa; es decir: para analizar, junto a los modos propios (lógicos y empíricos) de su funcionamiento, también las zonas oscuras, los prejuicios inconscientes o las falsas imágines, así como los intereses materiales, los mecanismos de control ideológico o los simples afanes de poder, que se mueven en el entorno - y que subyacen a la propia configuración metodológica - de eso, la tecnociencia, que ha sido el objeto de la descripción.

Porque de esto se trata, naturalmente. Según propone el propio término elegido, la situación a que alude la tecnociencia involucra que los constructos implicados en el par ciencia/técnica no son ya facilmente discernibles y que, así como la técnica es impensable sin el apoyo de la ciencia que le sirve de base, también lo es la ciencia sin los servicios que le proporciona el desarrollo de la técnica. Como lo resume G. Hottois, con referencia explícita al modelo tecnocientífico, "que la ciencia es técnica quiere decir, sobre todo, que la técnica constituye una mediación esencial de la relación científica con lo real» ${ }^{4}$. Pero, entonces, es completamente obvio que no puede ya apelarse al viejo reparto de papeles, todavía defendido por autores como Mario Bunge, según el cual «la ciencia básica es inocente, aunque la ciencia aplicada y la técnica puedan ser culpables» ${ }^{5}$. Incluso si se admite que ha habido algún tiempo en que tuviera sentido esta distribución de culpas e inocencias (lo que no es más, seguramente, que un resabio de la vieja ideología del cientifismo, sobre la que hace poco ha escrito, a mi parecer muy atinadamente, Antonio J. Dieguez ${ }^{6}$ ), es a todas luces irrelevante cuáles sean las intenciones que presiden, o han presidido, las actividades de quienes han destacado en una u otra de estas dos esferas, por cuanto ninguna de las dos ha podido situarse nunca al margen de su prolongación o

\footnotetext{
4 G. HotToIs, El paradigma bioético, Barcelona, Anthropos, 1991, p. 29.

5 Es el título de uno de los ensayos recogidos en M. BUNGE, Mente y sociedad, Madrid, Alianza, 1989, pp. 193ss.

6 Antonio J. DIEGUEZ, "Cientifismo y modernidad: una discusión sobre el lugar de la ciencian, en: J. RUBIO, El giro postmoderno, Philosophica Malacitana, Suplemento 1 (1993), pp. 81-102.
} 
aprovechamiento mutuos. Transcribo a este respecto lo que dice Dieguez, que me parece muy bien traído al caso: «No es posible seguir manteniendo por más tiempo la idea de que la ciencia es un conjunto de contenidos teóricos o de productos intelectuales que poseen un carácter objetivo y autónomo, al modo del mundo tres de Popper. Ni que la historia de la ciencia es la historia de los cambios de teorías que los científicos han ido efectuando en virtud de decisiones referidas exclusivamente al contenido de las mismas y a su relación con la evidencia empírica. La ciencia, además de consistir en teorías, experimentos, argumentaciones, decisiones racionales, etc., es una actividad encauzada en instituciones sociales y realizada por grupos de individuos, que, aunque son seres racionales, no lo son siempre, ni siquiera cuando hacen ciencia» ${ }^{7}$. En estas circunstancias, espero que Javier Echeverría no se enfade conmigo si me tomo a broma su afirmación de que yo soy «libre de pensar que la ciencia va a cambiar porque Lyotard, Vattimo y otros lo digan» (p. 133). Bien, soy libre de pensarlo, pero no, no pienso eso. Lo que pienso es que Lyotard, Vattimo y otros -entre los cuales están algunos, no exiguos en número, de los actuales sociólogos de la ciencia, como Knorr-Cetina o Woolgar (a quien ya cité en mi primer escrito), y otros más también, recientes o menos recientes, que no son sociólogos, como Polanji o Feyerabend o como Rorty o Wellmer ${ }^{8}$, que todos estos autores, digo, como yo con ellos, tenemos todo el derecho a preguntar si la situación del mundo, en la que se produce actualmente el fenómeno de la tecnociencia, genera condicionantes de la representación social y natural que, afectando de un modo

7 Art. cit., p. 89.

8 De Karin KnORR-Cetina, responsable, dentro de los estudios de la sociología de la ciencia, de lo que ha dado en llamarse el "constructivismo social", me refiero en particular a su The Manufacture of Knowledge: An Essay on the Constructivist and Contextual Nature of Science, Oxford, Pergamon, 1981. En cuanto a Steve Woolgar, cuyo programa de "etnografia reflexiva" lo convierte en el defensor tal vez más radical de cuantos postulan una epistemología crítica, su trabajo más representativo sigue siendo Science: The very Idea, 1986 (Ciencia: abriendo la caja negra, en la versión española de Anthropos, Barcelona, 1991). Los interrogantes abiertos por Feyerabend en Tratado contra el método (1975) son bien conocidos; pero, en mi opinión, resultan más convincentes desde el punto de vista crítico las argumentaciones de ¿Por qué no Platón?, Madrid, Tecnos, 1985. El libro de M. PolanYI Personal Knowledge: Towards a Post-Critical Philosophy, Londres, Routledge, 1958, es todavía un referente obligatorio contra el idealismo y la presunta neutralidad de los análisis filosóficos sobre la ciencia. Volveré a esta obra más abajo. Y, por lo demás, de los otros autores citados véase R. RORTY "Science as Solidarity", en Objectivity, Relativism and Truth, Cambridge, Univ. Press, 1991; y A. WELLMER, "La dialéctica de la modernidad y la postmodernidad", en J. PICO (ed.) Modernidad y postmodernidad, Madrid, Alianza, 1988. 
externo y no sólo externo a las estrategias de selección y conformación metodológicas de la actividad científica, pueden por eso mismo ser intervenidos, así en el plano teórico como en el práctico, a los efectos de ejercer la crítica de que, con toda razón, corresponde también ocuparse a la epistemología. Puede que a Echeverría esta pregunta o esta clase de planteamientos no le parezcan importantes. A mí me parecen ineludibles.

Y es que, desde luego, si se juzga por las tesis sostenidas en su ponencia inicial y, sobre todo, por las respuestas que (no ya, o no sólo a mí) da en su contestación, podría pensarse que esta finalidad crítica e intervencionista se halla ausente de su concepción de la epistemología. Es lo que yo pretendía decirle en mi primer escrito (también en el publicado por la Fundación March), al hacerle notar que expresiones como "poder dentro de las sociedades", "prácticas secretas", «instrumento de dominio», "grandes beneficios", y otras análogas que pueden extraerse de su texto (cf. p. 54), no tienen por qué ser aceptadas pacíficamente por la sola razón de que de facto y en la actualidad las cosas sean así; pero ahora veo que, incluso admitidos estos caracteres turbadores, entiende además que su postura es "racionalista e ilustrada" y que ello quiere decir que la tecnociencia constituye, a su parecer, «una mejora con respecto a la ciencia moderna» (p. 129). Estoy seguro de que en el marco de tal mejora no incluye "progresos" como los acabados de citar. $Y$ digo que estoy seguro, porque conozco bien su concepción axiológica de la ciencia, en la que el debate de los valores implicados en las actividades científicas ocupa un lugar del que no se excluyen los criterios de evaluación y control desde una multiplicidad de instancias teóricas y prácticas ${ }^{9}$. Esto lo sé, pues. Pero también creo saber (aunque en esto otro puedo equivocarme, naturalmente) por qué entonces ha recibido con tanta displicencia el que yo se lo recuerde, o el que, invitado a pronunciarse sobre el caso, no ya sólo por argumentos extraídos de la filosofía postmoderna, sino también — según puede comprobarse en el escrito de su contestación- por otros argumentos convergentes que derivan de la teoría de riesgos, haya dado en practicar el viejo ardid de ofrecer la callada por respuesta. No veo cómo puede sostenerse que los contravalores — los riesgos - «exigi-

9 Véase, entre otros textos, Filosofia de la ciencia, Madrid, Akal, 1995, cap. IV, así como, más recientemente, "El pluralismo axiológico de la ciencia», Isegoría, 12, 1995. Cierto es que en todos estos trabajos Echeverría practica siempre una misma estrategia de descripción, que se limita a presentar, no a cuestionar o a someter a crítica, los valores puestos al descubierto por su análisis. 
rán intervenciones adicionales», y no sólo por «los científicos (...), sino también por diversos agentes sociales, incluído el público en general» (p. 131), en una práctica tecnocientífica que previamente se ha descrito como dominada por el monopolio, el control por parte de sociedades transnacionales, el afán de lucro y el ejercicio sistemático del secreto. Echeverría debería explicar estas contradicciones flagrantes - no suyas, de la actividad tecnocientífica-, para las cuales me temo que la vaga confianza en el progreso o en la cogencia de los ideales de la Ilustración resulta tan sutil como especiosa. Pero, en fin, como lo dicen los alemanes: keine Antwort ist auch eine Antwort. Aunque, a mi juicio -y entiéndase: al menos en lo que se refiere a la materia de que a mí me corresponde dar cuenta-, la razón de esta paradoja se halla en la concepción que Echeverría se ha hecho de la postmodernidad y en el modo como, por ello mismo, cree que puede hacerse uso de este término en el marco de la epistemología contemporánea. Lo cual era, por cierto, tal como yo lo entendí, el tema que se trataba de debatir.

Porque lo llamativo es que Echeverría me acusa de equivocarme de debate o de querer hablar de filosofia postmoderna donde sólo era oportuno hablar de ciencia postmoderna. Y la prueba de ello, advierte, es que yo no cito a «ningún científico postmoderno" (p. 132). Esto último me regocija, pues no hay duda de que para una tal acusación se inventó el argumento tu quoque: su genérico análisis de la tecnociencia tampoco da lugar, efectivamente, a que él cite a ningún científico postmoderno. Sin embargo, dirigida a mí, es una acusación absurda, ya que lo que he sostenido en mi escrito y sostengo inequívocamente es que no existe una "ciencia postmoderna». O dicho de otro modo: lo que yo sostengo es que, por referirse la postmodernidad esencialmente a un cambio cultural, todo lo que la postmodernidad puede y tiene que decir sobre la ciencia consiste en averiguar si la forma como ésta se produce y ejerce -el rol que cumple en la sociedad, los valores que sostiene, los standards metódicos y epistémicos que prescribe y los factores externos con los que cohabita - son o no compatibles con los caracteres emergentes de esa nueva cultura; si no, dónde se hallan los deficits y las discrepancias y por qué merece la pena consignarlos; y, supuesta una contestación a estas preguntas, cuál es el papel que esa nueva cultura otorga a la ciencia y si es importante tomar en consideración las razones que le asisten para ello. Esto, 
digo, es lo que yo sostengo. Pero me veo obligado inmediatamente a añadir $-\mathrm{y}$ por razones sólo bibliográficas, al margen de mi intervención- que de esto es también de lo que versa el debate de la postmodernidad, sobre todo en lo que concierne a su relación con la ciencia. Basta con asomarse al diálogo entre Habermas, Lyotard y Rorty (y para ello basta, a su vez, con acudir a los libros, ya hoy elementales, de Foster o Bernstein o Harvey ${ }^{10}$ ), para comprender que el núcleo de la disputa reside en el diagnóstico, y en la evaluación subsiguiente, que podemos hacer del "proyecto filosófico moderno", para lo cual el criterio decisivo de demarcación (si bien no el único) es el significado y las pretensiones de aquello que se presenta, ambivalentemente, como su máximo logro o como su más inquietante mito: la constitución de la racionalidad científica. El hecho de que Habermas, en quien - no ya en esta polémica citada, sino en general- cobra cuerpo la defensa más firme de aquel proyecto moderno, parta, con todo, de una enérgica recusación del cientifismo, entendido, a la manera de Adorno y Horkheimer, como la ideología correspondiente al desarrollo de la producción capitalista en la última centuria, muestra con absoluta nitidez que el debate sobre la postmodernidad tiene un espesor teórico y una concreción de registros que no pueden satisfacerse con generalidades. Mientras que, al contrario, el hecho, ahora, de que Habermas conciba la «acción comunicativa» como un instrumento de orientación de la ciencia actual, a la que, como no podía ser menos, identifica con la tecnociencia, pero también con el legado de la razón ilustrada-y todo ello a fin precisamente de defender el proyecto de la modernidad contra sus detractores postmodernos-, prueba aún con mayor energía que la tecnociencia puede ser asimismo objeto de una consideración filosófica moderna o, mejor dicho, que modernidad y postmodernidad juegan aquí como opciones historiográficas dilemáticas respecto de aquel diagnóstico y evaluación a que acabo de referirme, sobre lo que, de todos modos, se presenta como un factum objetivo, no sujeto a disputa; o sea: la situación en que se halla hoy la racionalidad científica, expresada en el fenómeno de la tecnociencia ${ }^{11}$.

10 Cf. H. FosTer, La postmodernidad (1985), Barcelona, Kairós, 1985; R.J. BERNSTEIN, The New Constellation: The ethical-political Horizons of Modernity/Postmodernity, Londres, Polity P., 1991; y D. HaRveY, The Condition of Postmodernity, Oxford, Blackwell, 1990.

11 Cf., para la primera de las tesis, Ciencia y técnica como ideología, Madrid, Tecnos, 1981, así como el comentario de Teoría de la acción comunicativa, Madrid, Taurus, 1987, II, p. 469. Sobre la segunda tesis, véase, sobre todo, "Modernidad versus Postmodernidad", en J. PICO (ed.), Modernidad y Postmodernidad, Madrid, Alianza, 1988, pp. 87-102. La actitud de Habermas y, en general, la ambivalencia del legado de la Ilustración en orden al diagnóstico de la postmodernidad 
Ahora bien, es en el contexto de este examen, por lo demás bastante obvio, donde se hace patente cuál es mi discrepancia con Echeverría y por qué he juzgado necesario, más allá de cualquier prurito personal, responder a la breve contestación que ha dado a mis observaciones. La postmodernidad puede ser, en efecto, una noción compleja y, claro está, querellable; pero es una noción definida y estricta. Y yo creo que él no se hace cargo de ella o, dicho de otra forma, que rehuye su problemática básica por mor de una confusión que, pareciendo asistida del sentido común, esconde en realidad no otra cosa que un muy elemental desenfoque analírico. Toda la enjundia de la réplica de Echeverría se reduce a señalarme que, en virtud del sentido del adverbio post en las lenguas procedentes del latín, él se considera legitimado a utilizar la expresión "ciencia postmoderna" como simple apelativo cronológico de la ciencia que se practica "después de la modernidad" (incluso admitiendo que en varios respectos esa ciencia sigue siendo moderna). Es decir: afirma, $1 .^{\circ}$, que "ciencia postmoderna" debe entenderse sencillamente como "ciencia actual"; y, $2 .^{\circ}$, que, así considerada, la ciencia actual guarda algunos, o muchos, caracteres de la ciencia anterior, pero también añade otros distintos y lo suficientemente relevantes como para que se justifique la tesis de que implica un nuevo estadio en el desarrollo científico y se le otorgue por ello la denominación de "ciencia postmoderna" (p. 132). Bien, ¿qué decir de estas afirmaciones? Ante todo, que para un tal viaje no se necesitan, ciertamente, alforjas; pero también que, en ese caso, daría lo mismo que el debate se hubiese referido a "ciencia postanalítica" o "postestructuralista" o "post-segunda-guerra-mundial" o "post-muerte-de-Marylin». Dado que ninguna especificidad debe asignarse al término que se use, en virtud de la palmaria significación latina del adverbio post, todas estas expresiones resultan válidas, pues todas ellas pueden servir, efectivamente, como sinónimos de "ciencia actual», y a todas les casa de la misma forma remitir a un estadio nuevo de la ciencia, que, no obstante, conserva aún algunos caracteres del estadio anterior.

Sin embargo, que las cosas no son así, esto es, que Echeverría no buscaba conformar su análisis a una generalización tan de Perogrullo, y que de hecho no renuncia a usar el término "postmodernidad» en un sentido específico, lo demuestra el que, de todos modos, él parte de una determinación rigurosa, por más que sumaria, de la postmodernidad, a la que reconoce (siquiera sea

están bien analizados en R. J. BERNSTEIN, Beyond Objectivisme and Subjectivism, Oxford, Blakwell, 1989 , p. 189. 
implícitamente a través de su cita de Nebamou \& Caramello ${ }^{12}$ ) su condición de movimiento cultural; que acota después la obra de Lyotard (bien que sólo la de Lyotard y, aun ésta, sólo por la monografía de J. Rouse ${ }^{13}$ ) como referente de una filosofía postmoderna de la ciencia; y que sitúa, en fin, el objetivo explícito de su trabajo en diferenciar las «intuiciones postmodernistas» que juzga correctas de las que tiene por erróneas «en relación con la práctica científica contemporánea" (p. 48). Bien es verdad que en el texto impreso en el Cuaderno de la Fundación March Echeverría ha variado a veces y otras veces ha suprimido drásticamente algunos párrafos del escrito que sometió al debate público (que era, por cierto, el único de que dispusimos los que teníamos el encargo de responder). Pero tampoco estas modificaciones cambian sustantivamente el asunto. Los párrafos borrados, en los que Echeverría diseñaba una interesante crítica a la concepción, según él, "sólo lingüística" de la epistemología de Lyotard, constituyen una prueba a fortiori de que los intereses del ponente se dirigían no tanto a un análisis del estado de la ciencia "después de la modernidad" cuanto de la ciencia en relación con el pensamiento postmoderno; y ésta es, a buen seguro, una certeza que la mera eliminación de esos párrafos no logra disminuir. Como tampoco lo logran las variaciones introducidas en los otros párrafos a que me refiero, todas las cuales buscan aminorar ahora, o al menos relativizar en una proporción relevante, el malentendido de una cruda identificación entre postmodernidad científica y tecnociencia ${ }^{14}$. Por más que no deje de sorprender el método utiliza-

12 M. Nebamu \& Ch. Caramello (eds.), Performance in Postmodern Culture, Winsconsin, Centre for XXth Century and Coda Press, 1977. Nótese, en todo caso, que es ésta una monografía considerablemente antigua, que apenas se hace cargo de los problemas filosófi$\cos -\mathrm{y}$, menos aún, de los epistemológicos — planteados por la postmodernidad.

13 J. Rouse, Engaging Science, Ithaca/Londres, Cornell Univ. Press, 1996. Este es, en efecto, el libro citado por Echeverría. Pero, para una visión global de las corrientes de la actual Filosofía de la ciencia que, más allá de Lyotard, pueden asimilarse al pensamiento postmoderno hubiera resultado mucho más instruc-tivo otro ensayo del mismo autor; a saber, el titulado "The Politics of Postmodern Philosophy of Sciencem, Philosophy of Science, 58 (1991), pp. 607-27.

14 Me he referido a estas variaciones y supresiones experimentadas por el texto de Javier Echeverría en la n. 29 de mi anterior artículo (Revista de Filosofia XII, 1999, p. 142). De las primeras juzgo innecesario dar cuenta aquí. En cuanto al párrafo borrado rezaba así en el texto leído en la sesión pública:

"Mas vayamos a la tesis central de Lyotard. Coincido con él en que "el saber en general no se reduce a la ciencia, ni siquiera al conocimiento", pero disiento cuando afirma a continuación que "el conocimiento sería el conjunto de los enunciados que denotan o describen objetos, con exclusion de todos los demás enunciados, y susceptibles de ser declarados verdaderos of falsos; la ciencia sería un subconjunto 
do (que, por ejemplo, habrá convertido en enigmática mi respuesta a sus, para entonces, ya desaparecidas impugnaciones de la presunta concepción lingüística de la ciencia de Lyotard), yo no puedo, claro es, sino celebrar estas, Echeverría me tolerará que diga, «mejoras» de su texto, pues no se trata aquí de discutir por cualquier cosa, sino de colaborar a la clarificación del tema que nos ocupa. Al fin y al cabo, si él ha suprimido esos párrafos y ha matizado estos otros, será porque juzga lo que ahora dice más correcto que lo que sostenía antes. Con todo, y a pesar de ello, mi discrepancia con él subsiste en el mismo punto que ya le indiqué en mi primer escrito y al que igualmente se

de esos conocimientos". La concepción semántica en filosofia de la ciencia ba criticado desde hace dos décadas este reduccionismo linguiistico, que está presente por doquier en la obra de Lyotard. El conocimiento cientifico admite diversas representaciones semióticas (no sólo lingüisticas, por cierto), pero lo importante es que la ciencia no es sólo conocimiento, sino también acción e intervención en el mundo. Para ello, los cientificos utilizan instrumentos de medida, de observación y de experimentación que no pueden ser concebidos como entidades lingüisticas, por mucho que podamos hablar de ellos, descibirlos y formular reglas para su funcionamiento. A su vez, las instituciones cientificas, indispensables para la actividad cientifica, no son entidades lingüisticas. Y podriamos buscar otros muchos contraejemplos. En resumen: la reducción de la ciencia a conocimiento (epistemologia), y la reducción del conocimiento cientifico a su representación lingüistica ( $y$ enunciativa son dos de las grandes insuficiencias de la concepción standard en filosofia de la ciencia, que han sido ampliamente criticadas a partir de los años 80 (Sneed, Stegmüller, van Fraassen, Giere, etc.). Las concepciones de Lyotard sobre la ciencia no están suficientemente actualizadas, y ello supone un pesado lastre para su reflexión. La objeción es de peso, porque gracias a esta reducción puede contraponer el saber cientifico a los relatos, que sería, para Lyotard, la gran alternativa al conocimiento cientifico. Por mi parte, diré que lo importante es que algunos relatos (de base cientifica o no) transforman el mundo. El proyecto de la modernidad, desde Bacon, y sobre todo de la Ilustración, estriba en la transformación del mundo y de la sociedad gracias a la investigación cientifica, a las acciones técnicas y a la enseñanza obligatoria. Precisamente por ello la contraposición entre el discurso cientifico, pretendidamente unitario, y las narraciones y relatos, pretendidamente plurales, resulta desafortunada para pensar lo que es la ciencia moderna, y no digamos la tecnociencia. Para decirlo claramente: la ciencia no es reducible a juegos de lenguaje, como pretende Lyotard. Las bombas atómicas de Hiroshima y Nagasaki, por poner un ejemplo limite, son bastante más que juegos de lenguaje; $y$, desde luego, son ejemplos canónicos de la tecnociencia y de sus posibilidades para transformar el mundo. Reducir los aspectos pragmáticos de la ciencia a los actos de habla, como hace Lyotard, siguiendo a Wittgenstein y Austin, supone una simplificación inadecuada de la praxis tecnociéntifica»

En mi primer artículo (pp. 144-45 y n. 30) he mostrado ya la inexactitud que involucra la pretendida oposición entre "ciencia" y "relato" que Echevarría arguye en este pasaje. Y en cuanto al "reduccionismo lingüístico" de la ciencia, sobre el que también he dicho algo en ese mismo artículo (p. 143), nada es menos cierto que sostener que Lyotard no toma en consideración las instancias que refiere aquí Echeverría, del tipo de los «instrumentos" o las «instituciones científicas". Estas y otras instancias, como la "técnica» o el "dinero", forman parte, ciertamente, del análisis lyotardiano - y en una forma bien real y nada lingüística-, hasta el punto de conformar el carácter performativo que Lyotard atribuye a la teoría y la práctica científica contemporánea. 
refiere la consideración que acabo de hacer sobre el uso del adverbio post. El punto es éste: que la postmodernidad, lo mismo como filosofía sin más que como filosofía de la ciencia y, en uno y otro caso, como movimiento emergente de cultura, es inseparable de una crítica de la filosofia de la historia (de toda filosofía positiva de la historia) y que esta crítica no sólo ocupa una posición básica en su arquitectura de argumentación interna sino que constituye su dispositivo de impugnación fundamental contra la metafísica inmanente a la teoría del conocimiento moderno (incluído el conocimiento científico). Lo que se trata de comprender es, en primer lugar, que la simple disposición en el espectro del tiempo - la articulación de las situaciones imaginariamente denotadas en la estructura ante, nunc, post- no garantiza de ningún modo una acumulación cualitativamente progresiva del saber (o de la perfección moral, o de la felicidad pública), si no es mediante el acopio de filtros de discusión y análisis situados en el plano de un juicio exclusivamente sincrónico; $y$, en segundo lugar, que, en todo caso, tales filtros no son o no tienen por qué ser competencia exclusiva de eso que hemos dado en llamar racionalidad científica (algo así como si sólo los que participan de esta última, o sea, los expertos, estuviesen legitimados a pronunciarse sobre cualesquiera asuntos, debiendo reducirse todos los otros a la función de escuchar), sino que, al contrario, han de ser pensados y diseñados en forma que también el modo mismo de racionalidad que identificamos con la ciencia se vea sometido a ellos. Sobre la naturaleza y sobre las condiciones que deben cumplir tales filtros, tal como los concibe la filosofía postmoderna, algo he dicho en mi primer escrito ${ }^{15}$. Y, por lo demás, es este punto exactamente el que se nos solicitaba que debatiéramos en el Seminario público bajo la pregunta común de «si el modo de pensar científico (...) tiene el monopolio de la racionalidad" (pp. 13-14). Sólo me queda por añadir que, por todo ello, cuando yo he señalado a Echeverría que la postmodernidad no puede tomarse como un concepto cronológico, lo último que he querido es fastidiarlo con una cuestión academicista o, menos aún, urgirle a no "hablar o escribir correctamente»; lo que he querido es llevarle a la comprensión de una tesis - tal vez sería mejor decir, de un talante o una sensibilidad-, que él no tiene por qué aceptar si no le persuade, pero que tampoco puede omitir si se trata de pronunciarse sobre la postmodernidad en cualesquiera respectos con los que ésta se relacione $y$, por tanto, también en el respecto de la epistemología. 
Porque, para deslindar muy francamente nuestras mutuas posturas $-\mathrm{y}$ ya con esto acabo-, la cuestión es que Echeverría sigue la estrategia de juzgar, ante todo, a la filosofia postmoderna desde lo que él llama «la práctica científica contemporánea", para ocupar, después, el espacio que la refutación de aquella filosofía deja libre, por medio de una presunta ciencia postmoderna, que no es sino la ciencia misma que se hace, su factum histórico objetivo, o sea, la tecnociencia. Es palmario que, con ello, la tecnociencia aparece, simultáneamente, como un hito temporal (la ciencia que sigue a la ciencia moderna) y como la instancia que decide el significado mismo de la temporalidad (la ciencia que juzga a todos, no importa cuáles, los otros episodios del Espíritu). Pero no es menos palmario que, con ello, la tecnociencia aparece también como no sometible a crítica ni a otros controles que no sean los que ella pueda o quiera establecer desde la imagen que se hace de su propio autodespliegue. $O$ dicho de otra forma: que aparece como incapaz de todo distanciamiento respecto de sí misma y, por ello, como ajena, como puesta al margen del ejercicio de la reflexión. Al cabo, tal como yo veo las cosas, lo decisivo es esto ciertamente: que el modo de proceder de Echeverría coincide stricto sensu con el modo que he alegado en mi anterior escrito como propio de la episteme moderna; que él razona, en efecto, en términos de legitimación y ocupación de los espacios temporales en virtud de ideas o criterios que no tienen en realidad que ver con ningún criterio validable intraepistémicamente y sí sólo con un relato: el del progreso y control (siempre provisional, pero siempre efectivo) de la historia ${ }^{16}$. Ahora bien, quiero dejar constancia de que no le reprocho yo esta actitud, puesto que él mismo se define como "racionalista e ilustrado" (p. 129). Me limito a señalarle que, desde el punto de vista de la postmodernidad, esta es una actitud moderna; que no puede proyectarla, por tanto, en razón de un genérico argumento cronológico, a la tecnociencia, para inferir con ello alguna forma de identificación entre el estado actual de la ciencia y lo que él llama ciencia postmoderna; y que esto es así porque, aunque este uso del lenguaje pueda parecerle paradójico, la suya no es ya una actitud histórica, en el sentido en que a los hechos históricos les corresponde ser incontrovertibles y no tener marcha atrás, sino solamente, rigurosamente también, una actitud polémica, en el sentido ahora de que ya no comporta una convicción común, pacíficamente aceptada, que no pueda ser, que no sea de hecho, objeto de discusión.

16 Cf. art. cit., pp. 124-26 (y, supletoriamente, 128 y 132-34). 
Menos interesante que el debate con Javier Echeverría me resulta el que pueda sostener ahora con José Manuel Sánchez Ron; pero no ya porque su respuesta a mis observaciones se hayan producido en un tono que ningún código de cortesía me obliga a tolerar, sino principalmente porque se asientan sobre una profunda incomprensión - en realidad, no más que una radical ignorancia - de lo que significa la postmodernidad (así en filosofía como también en ciencia). Renuncio, desde luego, a glosar sus oscuras reconvenciones sobre los dominios de mi voluntad por la sencilla razón de que, siendo mía, no se me alcanza en qué pueda él meterse. Ya es el colmo que quiera controlar mis opiniones y también mis intenciones. Pero, por lo que se refiere a mi voluntad, el único ejercico que he hecho de ella ha sido plegarla (y precisamente porque él lo ha pedido) a la absurda exigencia de que quien replica tiene que ocupar menos espacio que quien predica. Yo le he hecho caso, en buena hora. No sé qué puedo hacer más por él.

Aunque quizá sí puedo: explicarle algunos lugares comunes, de los que tengo la impresión que no le constan adecuadamente. En realidad, todo el empeño de Sánchez Ron se cifra en presentar a la postmodernidad como un fenómeno que alude a la emergencia de un conjunto «de elementos políticos, institucionales o filosóficos, sociales en último término" (p. 29) y que se caracteriza "por la negación de un canon único y universal, el mundo de la reafirmación del pluralismo y la diversidad de valores" (p. 35). Como quiera que esto no es sustantivamente así —o sea, como quiera que esto equivoca la naturaleza del fenómeno en cuestión y además identifica sólo consecuencias colaterales en modo alguno relevantes para la crítica que la filosofía postmoderna hace del o, mejor, los modelos de la investigación científica-, se comprende entonces facilmente que pueda situar el debate de la postmodernidad en la «elección de los puntos de partida", una vez seleccionados los cuales todo deberá ajustarse, sin embargo, al así llamado y, claro es, por ser único y universal«método científico» (p. 123). Sánchez Ron entiende planamente que en la elección del "punto de partida (de la meta a alcanzar) son posibles otras racionalidades, es decir (?), otros sistemas de valores y justificaciones" (ibid.): otras racionalidades éstas, que, no obstante, deben cumplir, a su vez, la condición de ser «razonables», pues no es lo mismo elegir entre "construir un Superconductor" o "impulsar la física de semiconductores" que elegir entre cualquiera de estas dos posibilidades o cosas tales como "promover la ruptura 
de escaparates, la creación de agrupaciones de aficionados a las tres en raya o la práctica de la quiromancia" (p. 124). Punto en boca. Con estas mimbres pretende este historiador de la ciencia despachar el "postmodernismo", por algunos de cuyos aspectos declara, eso sí, "sentir simpatías" (p. 122). Ahora bien, precisamente porque él sitúa a la postmodernidad en ese espacio sociológico, anterior al espacio normado del método científico —el cual, por ello, debe entenderse como no susceptible de modificación por la naturaleza de los acontecimientos propios de aquel primer espacio-, por esta precisa razón le había hecho yo notar que los modelos epistemológicos que de este modo creen poder aislar los instrumentos de justificación y, particularmente, la lógica y la metodología de la ciencia —o sea, los modelos a los que es común llamar normativistas - encubren en rigor un conjunto de postulados inconscientes, o de simples prejuicios, por lo general atenidos a una visión acrítica de la historia ideal de los descubrimientos, cuya denuncia o, al menos, cuya discusión forma parte de las informaciones más elementales, más de primer nivel de enseñanza, que propicia hoy el estudio de la epistemología. Para esta discusión, el que Sánchez Ron se declare no normativista tiene muy poca importancia: en lo que concierne al significado de mi argumento es algo ciertamente que da lo mismo. Pero lo que me deja absorto es que él hace esta declaración en virtud de las dos siguientes pruebas: $1 .^{\circ}$, lo que ha escrito sobre Popper en su Diccionario de ciencia, que le libra, en su opinión, de "cualquier sospecha de popperianismo ferviente» (p. 127), y 2. ${ }^{\circ}$, que él es sólo un historiador de la ciencia y que difícilmente puede un historiador de la ciencia ser normativista (ibid.). Es escaso, desde luego, el margen de discusión que estas dos afirmaciones me dejan. La verdad es que en el sentido en que analizan a Popper las páginas a que me remite, nadie es popperiano; tampoco Popper ${ }^{17}$. Pero que resulte difícil ser

17 No se crea que es ésta una afirmación gratuíta o meramente retórica. El lector interesado en saber lo que dice Popper a través del Diccionario de la Ciencia de Sánchez Ron (Barcelona, Planeta, 1998, pp. 255-59) obtendrá tres únicas informaciones, las tres o falsas o triviales. Descubrirá, ante todo, que Popper forma parte de un grupo de filosófos fascinados por los éxitos de la física relativista y cuántica, tales como «los miembros del Círculo de Viena o los positivistas lógicos». Conocerá luego que, para identificar los caracteres que definen el método científico (lo que el intérprete identifica con el problema de la demarcación), Popper propone el criterio de la falsabilidad; el cual se ha demostrado incorrecto, pues "siempre es posible y lícito, además de frecuente, imaginar explicaciones para salvar nuestras teorías del dudoso veredicto de las observaciones". (Este argumento se prolonga, subsidiariamente, señalando que el falsacionismo, ¡qué gran contradicción! <sic>, se ha mostrado incompatible con la propia actividad científicopositiva de Popper en el campo de la mecánica cuántica). Y, finalmente, aprenderá que, de todos 
normativista porque se es historiador de la ciencia, constituye una tesis que le sugiero publique prestamente en la revista Science: causará revuelo. Pues el normativismo, en la forma en que se entendía hasta ahora, no consiste en la creencia de que es posible determinar «cómo debe ser tal o cual práctica, empresa o disciplina", sino en la convicción de que, cualesquiera que sean las circunstancias - históricas, sociales o psicológicas- que nos muestran su «pasado tal como fue» (p. 127), la ciencia se rige por un canon de racionalidad que puede y debe ser puesto al margen de tales circunstancias y que, como hemos

modos, la verdadera influencia de Popper se halla, no en sus doctrinas epistemológicas, sino en sus obras políticas, "utilizadas para defender una filosofía (y economía) liberal a ultranza", siendo en este preciso contexto donde encontrará una única y aislada referencia al Mundo 3, presentado por el autor, sin más, como el "mundo de los productos de la mente humana". C'est tout. Bueno, no todo, pues, si el lector que aquí imagino sigue aún leyendo a estas alturas, todavía podrá deleitarse con una conclusión de enjundia; a saber: la de que, a pesar de todo, «sabemos que, de alguna manera, Popper no andaba demasiado lejos de tener razón, y que su idea -idealista, desprendida, generosa, en este pragmático y tacaño mundo nuestro- de la investigación científica se aproxima a lo que la ciencia es o debería serm. Resulta entrañable esto de calificar al falsacionismo de idealista, desprendido y generoso; pero la verdad es que las incursiones de Sanchez Ron en materias filosóficas están siempre teñidas de un delicado lirismo, tras del cual no hay sino una apabullante vacuidad teórica. Su Diccionario trata, por ejemplo, de otros dos únicos filosófos: Aristóteles y Leibniz. Al primero lo reduce —-dado que de sus teorías nada queda - a que sostuvo que, para comprendernos a nosotros, hay que comprender el mundo, y viceversa; lo que, de todos modos, está bien, pues es cosa ésta, ay, que no se hace ya en los duros tiempos que vivimos. En cuanto al segundo, después de reconocerle sus contribuciones matemáticas, le acusa de que, no obstante, quiso imponer <sic> a la realidad dos conceptos <sic o exigencias. ¿Quiere saberse cuáles? Pues bien: la identidad de los indiscernibles y el principio de razón suficiente, esos mismos y no otros. En fin, para qué seguir. Los deslices filosóficos de Sánchez Ron empiezan a ser moneda corriente en el mundo académico. En una tesis doctoral sobre la filosofía de la matemática de Kant me encuentro con esta perla, seleccionada por el doctorando, Enrique Gómez Caffarena. Se refiere a la Introducción que Sánchez Ron ha dedicado al texto de los Fundamentos de la Geometría de Hilbert (Madrid, CSIC, 1991). El gran matemático alemán escribe: «Los axiomas de la Geometría podemos dividirlos en cinco grupos: cada uno de estos grupos, aisladamente, expresa ciertos hechos fundamentales correspondientes a una intuicións. Esto es congruente con la posición reconocidamente kantiana de Hilbert, para quien "todo conocimiento humano comienza con intuiciones, de éstas pasa a conceptos y termina con ideas" (Fundamentos, ed. cit., p. 1). Pero el prologuista no para en barras. Afirma sin inmutarse que "en todos «estos axiomas" se aprecia que están construídos en términos lógicos, no intuitivos, ¿cómo, si no, limitarse a decir: «Sobre una recta existen al menos dos puntos»? A cualquiera que haya dejado un resquicio a la intuición, que tenga la idea <sic de recta, no se le ocurriría reducirse a semejante enunciado, $o$, si lo hiciese, añadiría inmediatamente que existen infinitos puntos en una rectan. O sea: que reconocer al menos dos puntos le resulta a Sánchez Ron poquísimamente intuitivo; para serlo como Dios manda, debemos poder intuir el infinito de los puntos; y, si no, es que no hay quien entienda la idea - pues el concepto no parece bastante - de una recta. 
visto antes ( $\mathrm{y}$ en la opinión precisamente de Sánchez Ron, no en la mía) se corresponde con «el llamado ( $\mathrm{y}$ - ya lo sé - todavía mal comprendido) método científico" (p. 123).

Es verdad que algunos, como el Mr. Jourdain de Molière (¡de El burgués gentilhombre, no de El avaro, por favor!), saben hablar en prosa sin haberse dado cuenta ${ }^{18}$. No puede imaginarse Sánchez Ron hasta qué extremo estoy de acuerdo, salvo por el disparate de la cita, con esta sospecha que se autoinflinge. Sin embargo, la cuestión es que hay prosas y prosas, y que ésta que él sabe hablar sin haberse dado cuenta tiene algunos registros, para cuya comprensión es un requisito imprescindible eso justamente: darse cuenta de lo que se habla. Porque lo cierto es que, cuando de lo que se habla es del "método científico", la entera epistemología actual sabe que formula un problema, no una evidencia o una práctica común que pueda mencionarse, ingenua y confiadamente, como si denotara un objeto fácil de reconocer. Pero cuando además se comprueba que algunos de los perfiles de ese problema se incluyen entre los más importantes factores - quizás el decisivo- de cuantos explican la génesis de la actitud postmoderna de cara a la ciencia, entonces se pone meridianamente de manifiesto hasta qué punto es peligroso comunicarse en una prosa de la que casi todo se ignora. En realidad, como lo he explicado en mi primer escrito, el núcleo de la argumentación de Lyotard a propósito del metarrelato que la ciencia moderna hace de sí misma se ciñe precisamente a las consecuencias que podemos obtener del clamoroso fracaso en que ha incurrido la epistemología cada vez que ha tratado de describir en un sentido unívoco la naturaleza del método científico, cuya determinación, de haber sido posible, habría venido a permitir el logro del ideal cartesiano de la ciencia unificada. Y es que, en efecto, si no se supone que este fracaso se debe a que el método científico - como ya lo sabe Sánchez Ron- está "aún mal comprendido» y, por ende, que no hay por qué desconfiar del metarrelato de justificación de la ciencia, dado que llegará un día en que sin duda lo comprenderemos bien; si no se supone, digo, esto (que por cierto es la base de todo normativismo, incluso si se razona desde una actitud estrictamente falibilista), la alternativa que queda es pensar que el mentado fracaso no se debe a ninguna otra causa que no sea la de que la cosa que se busca —el método o, lato modo, la racionalidad científica - no existe

18 La frase en cuestión está, en efecto, en la escena $V$ del Acto II del Bourgeois gentilhomme y constituye uno de los pasajes más célebres y familiares del teatro de Molière. 
en ningún sentido autónomo, pues depende de configuraciones singulares relativas a las prácticas y creencias teóricas que en cada momento reconoce una comunidad humana organizada.

Esta es, como no se ignora, la alternativa que, desde el valor otorgado por Wittgenstein a los juegos del lenguaje y a la función constructiva de los usos, exploró Kuhn en los años sesenta; y, cualquiera que sean sus evidentes complejidades, cuya demarcación exigiría ponderar cuidadosamente lo que podemos entender por paradigma científico, esta es también la hipótesis en la que han venido trabajando, con posterioridad a Kuhn, los que hoy solemos designar como enfoques historicistas o sociológicos de la ciencia. Quiero advertir, ya que a menudo se habla de estos temas muy ligeramen-te, que una tal hipótesis no subvierte la posibilidad de referirse a un contexto de justificación para la ciencia, en una medida análoga a como la ejecución de diversos sistemas pragmáticos no subvierte la posibilidad de que todos puedan dar razón de sus usos en un marco de reducción interteórica (aunque sea relativa) para el que aún sea posible reconstruir una interpretación semántica común ${ }^{19}$. Esto sugiere, de acuerdo con la propuesta de Putnam en What Theories Are Not (1962) ${ }^{20}$, que cabe obtener un criterio de teoricidad que, al mismo tiempo que determine las coordenadas - o, mejor, las redes - en que se sitúa el "campo de lo científico", relativice, con todo, cualquier sentido unitario de la teoría, diluyéndolo en la serie real, históricamente producida, de las teorías o los saberes particulares. Con respecto a esta sugerencia, se puede dudar, naturalmente, sobre si la dirección infundida a los análisis conduce hacia una prioriación de la instancia semántica del modelo (en cuyo caso sería ésta quien tendría que presidir las reconstrucciones de las diversas disciplinas científicas) o, más bien,

19 Este es, como resulta obvio, el punto de vista de los ahora llamados enfoques semánticos o estruc-turalistas, de F. Suppe, W. Stegmüller o B. van Fraassen (cf. respectivamente, y por poner sólo algún ejemplo, La estructura de las teorias cientificas [1974], Madrid, Ed. Nacional, 1979; La concepción estructuralista de las teorias [1979], Madrid, Alianza, 1981; y The Scientific Image, Oxford, Clarendon Press, 1980). Aceptando los planteamientos dinámicos y externalistas de Kuhn, estos enfoques subrayan, en efecto, a través de técnicas de semántica extensional, la posibilidad de aislar y codificar la estructura común del conocimiento científico. Yo dudo mucho, desde luego, de que se pueda llegar a un tal resultado, en la medida en que remite a constructos precisamente pragmáticos, por medio de consideraciones extensionales; pero esta duda, que no cabe fundamentar aquí, no afecta a la sustancia del argumento que desarrollo en el texto.

20 Este artículo, uno de los primeros trabajos de Putnam, aparece ahora recogido en $\mathrm{H}$. Putnam, Mathematics, Matter and Method. Philosophical Papers, vol. I, Cambridge, Univ. Press, 1975. 
hacia una priorización inversa de las instancias pragmáticas (lo que, sin duda, vendría a instalar definitivamente la fragmentación en el seno de la filosofía de la ciencia). Tal como Lyotard formula el problema, según el cual el pluralismo y difusividad de los juegos de lenguaje científicos comportan ya la "situación" del saber, la última de las dos citadas perspectivas es la que resulta más conforme con el horizonte de una consideración postmoderna de la ciencia. Pero no hay que llamarse a engaño en este punto. Sea que se acepte este enfoque o su inverso, o sea, el enfoque semántico de Suppe, Stegmüller o Van Fraassen, lo que de una u otra forma se plantea aquí es que el "campo de lo científico" se ofrece como un resultado - y también, ciertamente, como un depósito- de las diversas actividades y codificaciones teóricas consideradas pragmáticamente, y no, desde luego, como una región autónoma, estatuida según los criterios unificados de un presunto método que pudiera pensarse en tanto que antecediendo y dirigiendo a los diferentes saberes. El dato decisivo es éste, en suma: que no existe la ciencia, sino las ciencias; o, dicho de otro modo, que, cualquier cosa que se designe con el nombre de ciencia, será siempre de orden derivado y constructo a partir de la producción material de los saberes. $Y$ es este pluralismo, en fin, éste y no el que resulta de vaguedades tales como las «elecciones razonables» o la "diversidad de los valores", el que constituye el fondo de la cuestión.

El fondo de la cuestión...: algo, en todo caso, que es ahora, después del absurdo rumbo que se ha impuesto a este debate, menos claro de lo que debería y para cuya comprensión, por ello mis-mo, aun a riesgo de volver a enfadar al irascible Sánchez Ron, no veo otro camino que introducir algunas precisiones, que delimiten, al menos, los perfiles más importantes del problema. Porque se hace preciso repetir aquí lo que he dicho más arriba. Y es que se puede estar de acuerdo o no con la impugnación que la filosofía postmoderna (y, como acabamos de ver, no sólo ella) hace de la presunta unidad epistemológica de la ciencia; pero lo que no resulta comprensible es que se pontifique sobre la «irrelevancia» de los planteamientos que le son propios (y aun de los de la filosofía en su conjunto, vaya por Dios), en un debate que trata precisamente de las relaciones de la ciencia con la postmodernidad. Incluso si fuera cierto - que tampoco lo es, como en seguida voy a mostrar- que esta clase de problemas tiene poco que ver con la «actividad» científica, entendida 
como "conjunto de conocimientos/contenidos" (p. 126), ello no daría derecho a Sánchez Ron a ignorar cuáles son los tópicos que fundan y desarrollan el significado de la postmodernidad, sobre todo si lo que se ofrece a cambio es una cosa tan estólida como la razonabilidad de invertir en física de semiconductores en vez de en técnicas de romper escaparates, pues éste es un asunto para cuya decisión se convendrá conmigo en que no es necesario poner en danza ni a la postmodernidad ni a otra cosa ninguna que no sea el más simple y escueto sentido común. A mi juicio, si se razona desde los análisis postmodernos ( $\mathrm{y}$, por tanto, desde las instancias que los identifican, no desde las que se invente un señor cualquiera, ayuno de informaciones), el sentido de un debate sobre ciencia moderna y postmoderna no puede ser otro que el de determinar, ante todo, cuál es el rol que la afirmación de la unidad y autonomía de la ciencia ha cumplido y sigue cumpliendo en los aparatos modernos de la configuración del saber; y, luego, si, en virtud exactamente de la naturaleza de la "actividad" científica y de la orientación que dibuja el marco de sus "conocimientos/contenidos", puede permanecer en ese rol, sin desbordarlo o, más aún, sin ponerlo ella misma en crisis. Esta pregunta —bifronte, según se ve- es la que tipifica en rigor la relación de la postmodernidad con la ciencia. $Y$ es a los efectos de responderla, incluso de poder formularla correctamente, donde cobra toda su importancia el problema que estoy tratando de dilucidar a propósito del fracaso en que hasta ahora ha incurrido la pretensión de referirse de manera unificada y unívoca al método o, en general, a la racionalidad científica.

Que esta pretensión hace ya mucho que resulta problemática, no es cosa, de todos modos, sobre la que haya que entretenerse demasiado. Por ceñirme a uno sólo de los requisitos que serían precisos para mantenerla (uno que no causa ya discusiones entre los estudiosos y sobre el que recientemente he escrito alguna $\operatorname{cosa}{ }^{21}$ ), tendríamos que poder afirmar, en efecto, que es posible construir una lengua de la ciencia basada en la universalidad de su forma, sólo en cuya virtud sería a su vez posible sostener la tesis del carácter unitario y autónomo de la lógica de la investigación y, por ende, del método científico. En La condition post-

21 Véase mi artículo "La resistible ascensión de Alan Sokal», Endoxa, 13, 2000, pp. 458 ss, cuyos argumentos resumo aquí. En este trabajo se encontrarán también, por lo demás, algunas otras razones, igual-mente tomadas de la crítica epistemológica, que asimismo laboran en contra de la pretendida existencia de eso que Sánchez Ron llama "el método científico". 
moderne 22 , Lyotard explora este requisito, concluyendo que no es sino parte del relato moderno de la ciencia, cuya fuerza de convicción reside únicamente en la exterioridad que confiere a esta última respecto de la producción material de los saberes. Dicha exterioridad, sostenida como elemento legitimador para justificar la posibilidad de aislar y reconocer en el plano de la forma enunciados de conocimiento puestos al margen de los límites y condicionantes de la lengua ordinaria, se hace patente en el hecho de que, si la afirmamos, debemos concluir entonces que la ciencia se produce fuera de los parámetros sociales e históricos de la construcción de los conceptos o, lo que es lo mismo, que demanda un habitat de producción y comunicación que es ajeno al de la lengua natural. Pero una posibilidad de esta clase, en la medida en que carga sobre la forma lógica la doble tarea de establecer las condiciones comunes para la construcción y también para la interpretación de las diversas axiomáticas científicas, choca inevitablemente con lo que, desde Ladrière, conocemos como "límites internos de los formalismos", que no es, como se sabe, sino el resultado de transpolar el teorema de Gödel del ámbito de la aritmética a todos los lenguajes artificiales ${ }^{23}$. En general, esto quiere decir que, si entendemos por axiomática la capacidad de construir un lenguaje que formula sus propias reglas (es decir, que comprende, como mínimo, la definición de los símbolos que serán empleados, la forma que deberán respetar sus expresiones y las operaciones que se permitirá hacer con estas últimas), si aceptamos además que para el ejercicio de esa capacidad es necesario que exista un metalenguaje que determine si y cómo un lenguaje dado satisface las condiciones formales de una axiomática, y si concedemos finalmente que un tal metalenguaje es el de la lógica, entonces, supuesto que la generalización del teorema de Gödel implica que ningún sistema formal puede satisfacer la condición de la completud, el metalenguaje lógico deberá usar, a su vez, de un metalenguaje de referencia para describir e interpretar cualquier sistema axiomático, no siendo ya este otro metalenguaje sino la lengua natural o cotidiana. Ahora bien, la lengua natural no es consistente con respecto a la negación: permite y produce ella misma paradojas. De modo que, al final, la construcción y aceptación de los sistemas axiomáticos no depende de

22 Ed. cit., cap. 11. Para un examen más detenido de la crítica global que el pensamiento postmoderno (no sólo Lyotard ni sólo la línea de análisis que desarrollo en el texto) elabora en relación a la presunta naturaleza unitaria de la racionalidad cientifica, véase de nuevo mi trabajo citado en la nota anterior, particularmente secc. III.

23 J. LADRIERE, Limitaciones internas de los formalismos (1957), Tecnos, Madrid, 1969. 
condiciones formales autónomas, derivadas del carácter incondicionado del lenguaje lógico, sino de un hecho distinto, ya no exterior sino inmanente a las condiciones mismas de la lengua cotidiana. Y tal hecho es el consenso - el pronunciamiento a su favor - en torno al sistema axiomático elegido, cuyas reglas resultan, por ello mismo, aceptadas por los expertos o, al menos, por su gran mayoría ${ }^{24}$.

Así, pues, la tesis que concede carácter autónomo, ideal-formal, a la investigación científica (sólo obligada, por ello, a dar razón ante sí misma) es no otra cosa que esto: un mito, una narración, que no procede de la praxis de las ciencias, sino del papel que la modernidad les otorga en el orden de su propia legitimación por el saber. Lejos de que los enunciados científicos de un orden dado tengan que atenerse a unas condiciones epistemológicas comunes y generales, que determinen su adscripción a la ciencia, lo que se les exige, en rigor, es que satisfagan (entre otros modelos o pautas de conducta de que no voy a tratar ahora) el modelo concreto de argumentación que ese orden dado reconoce como suyo $o$, lo que es mismo, cuyas reglas son aceptadas en particular por quienes forman la comunidad de sus expertos. Esto sugiere, como ya señalé en mi primer escrito, que, para avanzar en el ámbito de un saber cualquiera, al eventual investigador no le queda otra opción que, o bien acomodarse a los juegos argumentales estatuídos como propios de ese saber, o bien ser capaz de persuadir, en el caso de que genere un juego distinto, de la mayor bondad y eficacia de su nueva argumentación. Se reconocen aquí, como se ve, los cánones con que Kuhn (y Rorty) describen los periodos de ciencia normal y ciencia revolucionaria, habida cuenta de que cada introducción de un juego argumental inédito produce

24 A esto es a lo que se refiere, en suma, el reconocimiento que hace Kuhn en su ya clásica Estructura de la revoluciones cientificas, sobre que el acuerdo que preside los periodos de ciencia normal, no tiene - no puede finalmente tener otra fundamentación-que el prestigio de la autoridad cientifica, el normal funcionamiento de las instituciones docentes dedicadas a la transmisión de los saberes y, en última instancia, la intervención del poder político. Esta posición de Kuhn no puede asimilarse, de todos modos, a la que, con el mismo registro argumental, propone el pensamiento postmoderno. El carácter genérico de la tesis kuhniana la convierte, en efecto, en una tesis abstracta. No singulariza la clase de estructura material que organiza en cada caso la relación de todos aquellos (y otros posibles) elementos, de suerte que ni hace posible hacerse cargo, como lo argumenta Foucault, de la función necesariamente coactiva y en todo caso precientífica del paradigma en la genealogía de la ciencia, ni tampoco reconocer, como sostiene la actual etnometodología, la relevancia de los estudios sociológicos para el análisis de la actividad científica. Este último aspecto de la cuestión ha sido incluso formalmente rechazado por Kuhn, como se sabe. 
fenómenos que no son sólo epistémicos, sino tambien sociales que afectan, ciertamente, a la comunidad de los savants, de un modo que es de suyo imprevisible tanto para la presentación que ellos hacen del saber cuanto para el mantenimientos de sus mismas condiciones de vida. Pero lo decisivo, y lo que me interesa resaltar ahora, es que, en el marco que dibujan estos análisis, la cuestión de la ciencia cambia entonces de rostro, planteándose en una forma que es por completo diferente a la que propone el paradigma de la modernidad: en una forma, en efecto, que no se interroga ya por los caracteres epistemológicos del saber científico, sino por los constructos pragmáticos que definen - supuestos ciertos protocolos socializados de conducta- los juegos particulares de argumentación de los distintos saberes. Es palmario que, desde el punto de vista de la filosofía postmoderna, esto pone fin a la pretensión de que existan cosas tales como la racionalidad o el método científicos, en cuyo lugar sitúa la exigencia de dar entrada a un pluralismo de estrategias y metodologías, que no es previo ni exterior a la pragmática real de los saberes, sino interno, constitutivo de su propio desarrollo teórico. Ahora bien, si es cierto que un planteamiento de esta clase hace menos claro el rigor de esa presunta línea fronteriza que separa a la ciencia de cualesquiera otras actividades cognitivas, introduciendo a su vez una fuerte discontinuidad en los márgenes que comunican a los distintos saberes, también lo es que, al enfatizar de este modo la diversidad y el pluralismo, la filosofía postmoderna entiende que se limita a respetar la forma como en este punto se produce verdaderamente la praxis cientifica ${ }^{25}$. Y, por tanto, que, lejos de constituir, como tan a menudo se oye, un nuevo episodio en las actitudes irracionalistas o relativistas de la historia del pensamiento, esa misma filosofía puede ser también interpretada como un esfuerzo por liberar a las ciencias de los circuí-

25 Este es el sentido en el que un trabajo $-\mathrm{y}$, sobre todo, una línea de investigacióncomo la que en su día propuso M. Polanji ha podido convertirse, según señalé supra en la n.14, en un precedente del punto de vista postmoderno sobre la teoría de la ciencia. Al priorizar los aspectos locales y las prácticas particulares, en gran medida tácitas, de la producción efectiva de los saberes, Polanji pretendía que se diera de lado a toda precategorización ideal acerca de un fenómeno que sus propios análisis mostraban como inexistente: la ciencia. Pero no, entiéndase, a fin de impugnar, por ese medio, la racionalidad de los saberes, sino, precisamente al revés, para mostrar de un modo empírico la clase de prácticas racionales que esos saberes desarrollan en cada caso. Hay que añadir que el énfasis puesto por Polanji en la dimensión personal del comportamiento del cientí-fico, que en su libro de 1958 (Personal Knowledge, ed. cit.) cumplía una función deconstructora respecto de las idealidades supuestas en la epistemología de su tiempo, es suplido, en la perspectiva de la postmodernidad, por un énfasis diferente; a saber: como lo señalo en el texto, por el análisis de los discursos que identifican a las distintas ciencias. 
tos legitimadores que las condicionan, en nombre precisamente de una noción más depurada y plausible de la racionalidad.

Lo que acabo de exponer es bastante simple, muy de primer nivel en los estudios sobre el pensamiento postmoderno. Sin embargo, si me ha parecido preciso recordarlo, no es sólo, como he dicho antes, porque alguna claridad hay que poner sobre los problemas, sino también, en fin, porque, a esta luz, se comprende que no pueda yo aceptar el último de los adjetivos que me ha dedicado Sánchez Ron. Y es que, ciertamente, la interpretación pragmática de los saberes a que acabo de referirme, en la medida en que deja algún margen aún a la filosofía de la ciencia ${ }^{26}$, configura un nuevo y preciso programa de investigación, que se define stricto sensu por la necesidad de analizar y codificar las tópicas argumentativas fijadas en en el ámbito de las diversas prácticas teóricas. Este programa choca frontalmente contra los intentos actuales de recomponer un nuevo modelo de presentación común de la actividad científica, en este caso nucleado en torno a la biología, hasta el punto que, de haberse partido de una concepción menos banal de la postmodernidad (y, por ende, de no haber sido necesario dedicar un tiempo tan largo a explicar sus rudimentos), el debate de ciencia moderna y postmoderna podría haberse ceñido al estudio de este choque, que marca, sin duda, mejor que ningún otro acontecimiento, el estado actual de las cosas en el interior de la epistemología. No es posible entrar en este asunto (queda, pues, pendiente), pero su mera cita sirve para establecer la especificidad a que el citado programa postmoderno apunta. Se trata de abolir todo recurso a factores sustan-

26 Es decir, en la medida en que no tiene que limitarse $y a$ al estudio de las actividades particulares o, como lo he dicho antes, de los protocolos socializados de conducta que promueven o son propios de los distintos saberes. Un tal estudio es el objeto de la actual sociología de la ciencia (en sus diversas variantes) y no hace falta decir que en él se disuelve cualquier pretensión de validez de la filosofía de la ciencia, pues no es el caso que tales actividades o protocolos sean homogéneos o puedan reducirse a un esquema común. El hecho de que el único elemento que se repite, invariable por más que heterogéneamente, en todas las prácticas teóricas sea el uso de argumentaciones (de discursos), convierte a la sociología de la ciencia y a los programas de la postmodernidad en perspectivas necesariamente complementarias, como S. Woolgar y $\mathrm{M}$. Ashmore han com-prendido antes que nadie. Cf. del primero, Knowledge and Reflexivity: New Frontiers in the Sociology of Knowledge, Londres, Sage, 1988; y del segundo, The Reflexive Thesis: Wrighting Sociology of Scientific Knowledge, Chicago, Univ. Press, 1989. 
tivos de análisis - los cuales, merece la pena reseñarlo, siempre pueden traducirse a un orden pragmático de consideraciones- en favor de una reconstrucción sistemática de aquellas tópicas argumentativas de que usan y por las que se autodefinen los saberes. $\mathrm{O}$ sea: se trata exactamente de supe-rar el punto de vista del método, a fin de establecer la retórica de las ciencias. Sin embargo, Sánchez Ron me acusa de esto mismo, como si ello me descalificara definitivamente. Yo dice él- tengo «una visión retórica de la ciencia, que no es capaz de entender el por qué <sic> es precisamente ahora cuando la cuestión del postmodernismo ha penetrado en el mundo científico» (p. 126). Es difícil imaginar un dislate mayor, cuando se considera que «la cuestión del postmodernismo» resulta ser finalmente, esencialmente también, la cuestión de la retórica de las ciencias. Pero, por eso, me resul-ta un absoluto enigma saber a qué se refiere en realidad Sánchez Ron con su comentario. ¿Quizás a la retórica en el sentido en que Marcelo Pera ${ }^{27}$ ha establecido consistentemente la conexión estructural entre determinados esquemas retóricos y los modelos concretos de argumentación de diversas ciencias? ¿Será más bien a los análisis de Mulkay ${ }^{28}$, para quien la naturaleza específica de los problemas da lugar a intereses cognitivos concretos, y éstos a prácticas argumentativas especializadas, que no son plenamente conmensurables de saber a saber? ¿O puede que aluda a la teoría argumental, ya bastante antigua por cierto, de Toulmin ${ }^{29}$, cuya presentación como una tarea que atafie precisamente a la epistemología él mismo ha puesto de relieve? ¿O no serán estos análisis sino aquéllos con que Paolo Fabbri y Bruno Latour, aunando perspectivas sociológicas y semióticas en el examen de un artículo de endocrinología, han intentado aislar las figuras o procedimientos específicos de la "retórica de la ciencia" ${ }^{30}$ ? $\mathrm{O}$

27 M. PERA, Scienza e Retorica, Roma, Laterza, 1991.

28 M.J. MULKaY, Science and the Sociology of Knowledge, Londres, Allen \& Unwin, 1980. Cf., igualmente, M.J. MULKAY, J. POTTER Y S. YEARLEY, "Why an Analysis of Scientific Discourses is Needed", en: K. KNORR-Cetina y M.J. MulKaY (eds.), Science Observed: Perspectives on the Social Study of Science, Londres, Sage, 1983.

29 S. Toulmin, The Uses of Argument, Cambridge, Univ. Press, 1958.

30 P. FABBRI \& B. LATOUR, «La retórica de la ciencia: poder y deber en un artículo de ciencia exacta" (1977), en: P. FABBRI, Tácticas de los signos, Barcelona, Gedisa, 1995, pp. 265-89. Mediante un análisis semejante Giora Hon se ha referido igualmente, en la reunión de Torino (1998) del grupo IASC, a la "retórica del experimento científico", estableciendo también en este ámbito -que parece tan vinculado a prácticas empíricas- la competencia de una doctrina argumental. Véase G. HON, "L'esperimento come argumentazione», en La retorica dell'esperimento scientifico, Torino, en prensa. (Las siglas IASC traducen International Association for the Study of Controversies). 
aquellos otros, tal vez, por medio de los cuales los miembros del programa EPOR, y particularmente Harry Collins y Trevor Pinch ${ }^{31}$, han descrito, a su vez, los mecanismos de índole retórica que permiten el cierre de las controversias científicas mediante una limitación de los modelos argumentativos considerados aceptables?

Pero son vanas estas preguntas. No hay peligro de que Sánchez Ron tenga consciencia de estas nuevas prosas, en las que (y supongo que aquí también como el "avaro" de Moliére) habla sin haberse dado cuenta de ello. Sin embargo, y dicho esto con mayor respeto del que él ha tenido conmigo, la cuestión es que estas prosas no son accidentales a los "conocimientos/contenidos" generados por las actividades científicas, puesto que remiten al modo como éstas se producen y, por tanto, a la clase de informaciones que ofrecen. Se puede, como es obvio, cuestionar o relativizar el alcance de estos análisis en orden a proponer una explicación comprehensiva de los fenómenos implicados en la práctica de los saberes, tal como, contestando a Latour, ha hecho S. Shapin ${ }^{32}$. Pero no se los puede ignorar olímpicamente, como si no existiesen o no tuviesen nada que decir, y no sólo porque corresponden sensu stricto a la sustancia del debate que nos ocupa, sino sobre todo porque, sin ellos, las ciencias se enajenan de la reflexión sobre sí mismas (se hacen ciegas, por ejemplo, al mito de la ciencia), de suerte que exhiben sus productos como si se tratase de sucesos históricos sin más, sólo requeridos de narrar la ocasión o las circunstancias o los procesos particulares que han determinado la lógica de su invención, todo ello en el espíritu del positivismo más ingenuo. Seguramente es este punto el que nos separa de un modo irreductible a Sánchez Ron y a mí. Pero, en fin, dejando ya defi-nitivamente al margen sus puntos de vista, que, la verdad, afectan poco a la hermenéutica del pensa-miento postmoderno, lo que importa comprender es que, si se admite que el pluralismo de los méto-dos y las estrategias teóricas, pertinentemente objetivados en tópicas argumentales, constituye el criterio más plausible para describir la situación en que en la actualidad se halla la praxis científica, entonces esta misma situación no puede sino generar el

31 Véase, sobre todo, H.M. Collin, Changing Order, Londres, Sage, 1985; y H.M. Collins \& T. PINCH, The Golem: What Everyone Should Know about Science, Cambridge, Univ. Press, 1993. Las siglas EPOR traducen, como se sabe, el Empirical Programme of Relativisme, cuya dedicación básica - hasta ahora - ha sido el análisis de controversias científicas contemporáneas.

32 S. SHAPIN, "Following Scientists Around", Social Studies of Science, 18, pp. 533-50. (Es una reseña de la obra de B. Latour, Science in Action, de 1987). 
fenómeno que ya antes he anunciado; o sea: su pugna, su conflicto dialéctico con el relato global de la legitimación del saber y, por tanto, con la afirmación de que existe un algoritmo que define el "método científico" y, con él, el modelo, el canon de toda racionalidad epistémica.

$\mathrm{Y}$ en esto estamos. Aunque no, ciertamente, en una forma que afecte ya sólo a una cuestión (o a un orden de cuestiones) de naturaleza metacientífica, sino también, y antes que eso, de pura y simple alienación ideológica, puesto que lo que se juega en el entorno de esta pugna es si triunfará una cultura de la diversidad y la diferencia o de la homogeneidad y el pensamiento único, este último puesto al amparo del recurso al juicio inapelable de los expertos cientificos. En realidad, la crítica que el pensamiento postmoderno hace a la idea "moderna" de la ciencia se ciñe en última instancia a esta final dimensión ideológica del asunto. El mundo que vivimos, sobre todo en el interior de las sociedades desarrolladas — que, por lo demás, son las que controlan el cien por cien de las fuentes de producción de imágenes- nos suministra ejemplos innúmeros de un modo de proceder, según el cual no importa de qué cuestión se trate o qué problema sea el sometido a consideración, pues es ya sencillamente inimaginable que la decisión final no esté avalada por un dictamen de expertos, que siempre posibilitará la defensa de esa decisión en virtud del presunto carácter científico de los enunciados teóricos que incorpora, sin que haya lugar a otras alternativas. Claro está que, puestas así las cosas, tampoco importa que aquellos enunciados teóricos respondan a standards de prescripción muy diferentes, según las áreas del saber llamado a consulta. Se reconoce, como no puede ser menos, que tales standards son muy dispares y que los requisitos que deben cumplir, digamos, en física nuclear o en genética son de un orden de exigencia no ya muy superior, sino sobre todo muy distinto al que se les reclama, digamos ahora, en sociología o economía. No obstante, por mucho que esto pueda ser influyente en lo que atañe a la plausibilidad de los saberes (pues ya se sabe que no todos han llegado aún al mismo grado de progreso), no lo es en absoluto en lo que concierne a su función de legitimación, para lo cual basta con que los enunciados propuestos en cada caso puedan exhibir (esto es, presentarse a si mismos diciendo) que forman parte del universo de la ciencia. Al cabo, todo consiste en creer y hacer creer que una tal cosa existe: la ciencia, la racionalidad científica un canon común, reconocible en sus signos y caracteres formales, capaz no sólo de proporcionar conocimientos seguros en todos los dominios, sino también de establecer una firme línea fronteriza entre lo racional y lo irracional, lo aceptable y lo 
denegable, lo sujeto a confianza o recelo. Que esta creencia tiene grados, que el valor relativo de los informes del saber constituye un factor ponderable de las decisiones, que el conocimiento y la praxis guardan, en fin, formas complejas, pero no inasibles, de relación mutua, todo esto está tan fuera de duda como también su contrario. Es decir: como la incitación constante a que la ciencia se convierta en un poder, que no sería ciertamente el del conocimiento, pero en cuyas tramas, extendidas a todos los substratos, incluso los más capilares y microfísicos, del sistema social, terminaría por abolirse cualquier pluralismo, incluído el de los saberes, restringiendo al mínimo en el caso de estos últimos su propia proliferación y heterogeneidad metodológicas.

No es descartable, desde luego - al contrario, son muchos los indicios que lo anuncian - que esta última posibilidad pueda consumarse a escala planetaria. Sin embargo, si se estima que es deseable y oportuno oponerse a este resultado -lo cual define el territorio de una decisión de, no de un asalto a, la razón, el único procedimiento que todavía me parece posible es el de incidir en la naturaleza plural, heterogénea de los saberes, lo que, en resumen, significa el de liberar la praxis cientifica de las presiones, es verdad que inmensas, del metarrelato del saber. En este punto, como en otros que remiten a la situación de nuestra cultura, un tal procedimiento es el que, tentativamente, con luces y sombras, identifica hoy al programa de trabajo de la filosofia postmoderna. Y la intención de estas páginas, no al margen pero sí más allá del presente debate, es dejar constancia de ello. 